JOURNAL OF THE AMERICAN SOCIETY FOR INFORMATION SCIENCE, volume 48, issue 5 (May 1997), p. 442 - 445. (c) 1997 John Wiley \& Sons, Inc.

ISSN: 0002-8231

DOI: 10.1002/(SICI)1097-4571(199705)48:5<442::AID-ASI8>3.0.CO;2-v

\title{
The Implementation of the Integrated Information Center at the University of Minnesota
}

\author{
Joseph Branin \\ Dean of Libraries, State University of New York at Stony Brook, Stony Brook, NY, 11794-3300.
}

\section{George D'Elia}

Center for Applied Research in Library and Information Science, School of Information and Library Studies, State University of New York at Buffalo, Buffalo, NY, 14260-1020.

The implementation and operation of the Integrated Information Center (IIC) can be divided into three, relatively distinct phases corresponding roughly to the 3 years of the grant, from October 1990 to September 1993. This article presents the story of each phase of the implementation.

\section{Phase I: October 1990-August 1991}

The project commenced with the assumption that the proposed model Integrated Information Center (IIC) would be implemented. As originally envisioned in the proposal, the IIC was to have taken the lead in the management of the information technologies and resources of the two academic units. The management of the information systems functions within those academic units, while not necessarily subsumed entirely within the IIC, was to be a primary responsibility of the IIC. The creation of the School of Management's Office of Information Technology (OIT) and the hiring of its manager coincided with the beginning of the IIC project. The Manager of OIT as well as the Manager of Information Resources in the Institute of Public Affairs joined the planning effort for the IIC project. The Planning and Implementation Team spent a substantial part of the first year of the project in discussions about boundaries between the IIC and the emerging information centers within the School of Management (SOM) and the Institute of Public Affairs (IPA) pertaining to areas of responsibility regarding management of technologies, services to be provided, and clients to be served. The Planning and Implementation Team had difficulty reaching consensus on these jurisdictional issues and on the scope of the mission of the IIC relative to the other information centers.

As the Planning Team continued to meet during the first year of implementation, it became evident that there was growing competition and conflict of interests between the IIC and the emerging SOM and IPA information centers. In order to resolve these issues of boundaries, a revised organizational model was adopted which became known as the "Mickey Mouse", model-Mickey's head was the IIC and his ears were the SOM and IPA information centers. The ears represented the gateways for the flow of information to and from the primary client groups - the faculty and staff of the two units. This revised model incorporated all of the functions and services of the IIC, as outlined in the proposal, but represented a new organizational alignment between the IIC and the SOM and IPA information centers.

\section{Phase II: August 1991-May 1992}

During this phase of the project, it became apparent that, rather than operating as gateways to the client groups, the information centers in the two schools, the ears of the "Mickey Mouse" 
model, were operating more as gatekeepers constraining contact with the client groups and generally inhibiting the development of the IIC. The reasons for the difficulties encountered during this phase of the project appeared to have been due to the need for organizational differentiation, that is, the need of each of the information centers for organizational identity, credibility, and success. Individuals on the staffs of these centers had different responsibilities, different opinions about how best to provide information services and support, different time horizons, different interpersonal styles, different managerial objectives, different reporting lines, and different reward systems. While there was agreement in principle about the need for collaboration, there often times was disagreement about the priority of given projects, which center was to be responsible for managing the projects, and how to accomplish the objective. This need for differentiation manifested itself in disagreements over "turf" during this phase of the implementation. These "turf "' issues pertained mostly to areas of responsibility, access to clients, management of networks, and accountability for the performance of technologies or services. The reader should note that while these organizational dynamics are discussed below singly, they appeared to have been operating interactively.

First, the managers of the SOM and IPA information centers appeared not to value the goals of the IIC project nor to place high priority on many of the activities of the IIC. Both of these managers were confronted with the many problems associated with the building and management of their respective networks, as well as with an explosive demand from their endusers for support services. Their available resources were not adequate to meet demand. IIC projects, which were primarily related to the provision of scholarly resources, required that the information centers redefine or expand their areas of responsibility. Given their scarce resources and further given that from the perspectives of their crowded agendas the IIC projects were tangential to their areas of responsibility, the two information centers were reluctant to commit resources to IIC projects or to engage in collaborative innovations. Under these conditions, it was very difficult to get and to keep their attention focused on IIC related projects. The attendance of these managers at the IIC Management Team meetings was sporadic, making planning and collaboration difficult. The priority that they assigned to IIC projects was also low. IIC projects, requiring action from these managers, oftentimes were delayed weeks or months because of inaction due apparently to nothing more than the low priority they assigned to IIC projects compared to their other more pressing projects. For the two information centers, these delays were business as usual. For the staff of the IIC, these delays, in the context of a 3-year project, seemed interminable and produced considerable frustration.

Second, the managers of the SOM and IPA information centers were very much concerned with control of their systems as embodied in the management of technology, support of applications, and consistency of service. Failure in any guise reflected badly both on the information centers and their managers. Risk-taking for them, while at times unavoidable, was to be held to a minimum and then only with adequate planning and pre-testing. The IIC, on the other hand, was an experimental entity with a mandate for innovation and experimentation. For the IIC, the potential for failure was an acceptable risk. The IIC considered itself to be an alphasite; the two information centers considered themselves to be operational service units held accountable for the consistency and quality of their services. This difference in orientation manifested itself every time that the IIC mounted a database and attempted to make it available as a menu option over the networks, for example, Lexis/Nexis, Wilson Business Abstracts, Dun \& Bradstreet Credit Databases, and a variety of CD-ROM databases. The SOM/IPA information centers would test the databases and would refuse to make them available on their networks until 
all the bugs were worked out. In their opinion, any lapse of service would reflect badly on their operations.

The managers of the SOM and IPA information centers were also very concerned about the IIC creating demand for services which were not part of their mission. They were concerned that, when the IIC Project was over, they would be left with the responsibility for maintaining the services without any commensurate increase in resources.

Third, the managers of the SOM and IPA information centers were very concerned about differentiating themselves from the IIC and were reluctant to give the IIC any visibility. They refused to make access to the IIC network available from their network menus and they refused to give the IIC a mail box on the E-mail system. While the manager of the IIC, as an adjunct member of the School of Management faculty, had a mailbox on the school's network, the librarian in the IIC was refused a mailbox on the grounds that mailboxes on the School's E-mail system were limited to School members. It was claimed that to admit an outsider would open the floodgates for demands by others outside of the School for a mailbox. To the IIC this was an issue of cooperation; to the SOM network this was an issue of control. It took about 6 months and the direct intervention of the Project Director to get a mailbox on the SOM network for the librarian in the IIC.

When the IIC announced its intention to interview faculty in preparation for a current awareness service, the manager of the SOM information center objected on the grounds that these faculty were her responsibility, that services to these faculty were the responsibility of the SOM information center, and that the role of the IIC was to support the activities of the SOM information center. The manager of the IPA information center agreed but selected only four faculty that the IIC could interview. He was concerned about creating demand for services that were not, and might not become, available.

Up to this point in the project, the attitude of the Project Director and other key members of the project team had been one of patience engendered by a commitment to the model and a belief that the efficacy of the model would ultimately prevail. Unfortunately, the isolation of the deans of the two schools with respect to these operational difficulties and their reluctance (or lack of interest) to become involved led eventually, in May of 1992, to a decision by the Project Advisory Committee to abandon the "Mickey Mouse" model of organization and to forego the attempt to integrate administratively the three information centers. The Project Advisory Committee empowered the IIC to act more or less independently of the other two information centers in the development and provision of services. This new organizational relationship was characterized as a "string of pearls" model - three organizationally separate but networked information centers, together striving to provide to faculty and staff the information technologies and services outlined in the original proposal. The IIC staff was empowered to move ahead quickly in offering services to end-users in the School of Management and the Institute of Public Affairs without the prior approval of the information centers within those two schools.

\section{Phase III: May 1992-September 1993}

With the adoption of the "string of pearls"' organizational model, the boundaries between the IIC and the other two information centers, defined in terms of both organization structure and mission, became clearer. Organizational differentiation was established and the problems associated with interdependency among the three centers were diminished. The IIC serviced the scholarly information requirements of the School of Management and the Institute of Public Affairs, while the information centers within those schools managed the networks, computer 
technologies, and administrative information systems of their respective schools. The three centers continued to cooperate in those areas which were mutually beneficial, most notably, joint development of research databases, student information databases, user education, and consultation services.

During this last phase of the project, the IIC, while continuing to work closely with the faculty and staff of the School of Management and the Institute of Public Affairs, became more of an outreach agent of University Libraries. Its control and loyalty passed from the School of Management and the Institute of Public Affairs to the University Libraries. While, with the adoption of this new organizational model, the tensions between the IIC and the SOM and IPA information centers eased, tensions between the IIC and various library units increased. Although University Libraries played a key role in the IIC Project throughout its planning and implementation phases and became the chief champion for the IIC by Phase III, collaboration between the IIC and the library staff and units was at times problematic. During the course of the project, there were conflicts over responsibilities, competition for the allocation of dwindling resources, differences in approaches to problem solving, and some misunderstandings or lack of interest in the project that lead to disputes, or at least distrust, between the new IIC and the established library units. Conflicts associated with organizational differentiation and competition now arose with library units as the IIC was perceived as encroaching on long-established areas of library responsibilities.

Business Reference Services and the Government Publications Library were two library units most closely associated with the IIC. Overall these units worked well with the IIC, but at the outset of the project, there were concerns expressed by their staffs about duplication of effort and there were some initial conflicts and confusion over similarity of responsibilities. Eventually, service responsibilities were defined for the IIC that extended or complemented the existing services offered by Business Reference Services and the Government Publications Library. These units came to collaborate closely on selecting and networking databases, on providing consultation to faculty, and on offering workshop presentations.

Another reason for conflict appeared to be some marked differences in approaches to problem solving. In general, units within University Libraries tended to be bureaucratic, that is, slow and careful in responding to new service needs. The IIC, in contrast, was entrepreneurial, innovative, and under pressure to get things done during the project. It wanted to move quickly in establishing new services. The two best examples of these conflicting approaches arose over issues of indexing company annual reports in Business Reference Services and over the mounting of the Current Contents databases. In both these cases, University Libraries and the IIC acknowledged the need for these services, but University Libraries had not been able to allocate resources to fit them into standard operations. The IIC proposed handling both these needs in nontraditional ways. Company annual reports would be indexed on a microcomputer database, and Current Contents would be mounted on Gopher. ${ }^{1}$ With the threat of company annual reports existing on a separate database not integrated into LUMINA (University Libraries' online catalog) and being done without following cataloging standards, the Technical Services Unit with some assistance from the IIC and Business Reference Services found a way to get company annual reports cataloged on LUMINA. The IIC did proceed with mounting Current Contents on

\footnotetext{
${ }^{1}$ Gopher is software, developed at the University of Minnesota, for tunneling through a TCP/IP Internet. The Internet Gopher client/server provides a distributed information delivery system around which a world/campus-wide information system (CWIS) can readily be constructed. While providing a delivery vehicle for local information, Gopher facilitates access to other Gopher and information servers through the world.
} 
Gopher. This database was mounted quickly and inexpensively and has generally been praised by faculty who use it. However, some University Libraries staff remain critical of it, claiming that the search engine is not sophisticated enough for a research library's purposes.

Finally, conflict occurred at a most basic level over the allocation of resources. The three years of IIC implementation occurred during a period of small but steady budget reductions in University Libraries and the whole University. This made competition for limited resources more intense. With grant funding for the IIC ending at the completion of Phase III, not all library units supported the reallocation of resources to continue the IIC. With established and basic user services, like library hours, being cut back, there was only mixed support for the IIC. The IIC was an agency of change and it appeared that it was not always welcomed by established units in whatever relationships it attempted.

While these organizational issues were nettlesome and never completely resolved, technological advances created new possibilities and much work for all information providers on campus. The campus infrastructure for networked information services had matured, and the University's central information delivery systems and departmental support units were rushing to provide new services to end-users. Demand from these end-users for information resources and for technological support was increasing and straining the ability of any one center to satisfy it adequately. In this environment during phase three, the IIC began to serve as a moderator, if not a real integrator, for communications between the University's central information delivery systems and the SOM and IPA information centers. It focused its attention on the delivery of scholarly information resources and services to faculty and staff, forged links with Computer and Information Services, and began delivering scholarly information services over the campus network. The IIC effectively exploited the opportunities presented by new models of clientserver computing, becoming an advocate and agent in University Libraries for use of Gopher. The IIC brought staff from the University Libraries and Computer and Information Services together to offer a current awareness service using Current Contents databases on Gopher. The IIC also became a center for new information technology and literacy training activities for staff from University Libraries, and faculty and staff of the School of Management and the Institute of Public Affairs. The IIC provided facilities, equipment, and staffing that brought together information providers from all levels on campus to offer a wide range of workshops, presentations, and hands-on training on information technology and literacy topics. The IIC was uniquely placed and staffed to support enduser demands that cut across the levels and jurisdictional boundaries of the information providers on campus. But collaboration and integration occurred on a project by project basis rather than on an ongoing basis. In the final year of implementation, the IIC provided many different services for and to University Libraries, the School of Management, and the Institute of Public Affairs, but it did not really become an integral part of any other information provider's operation. The established organizational boundaries were never broken. 